See discussions, stats, and author profiles for this publication at: https://www.researchgate.net/publication/26120883

Experimental approach to an optical wireless interface for an avionics data bus

Conference Paper · October 2012

DOI: 10.1109/DASC.2012.6383108

CITATIONS

4

4 authors, including:

6. Javier Perez-Mato

Universidad de Las Palmas de Gran Canaria

4 PUBLICATIONS 12 CITATIONS

SEE PROFILE
READS

206

Rafael Pérez-Jlménez

8. Universidad de Las Palmas de Gran Canaria

137 PUBLICATIONS 1,188 CITATIONS

SEE PROFILE

Some of the authors of this publication are also working on these related projects:

Project URBAN WASTE, H2020-WASTE-2015-two-stage, Ref. 690452. View project

Project Innovative NDT technique based on ferrofluids for detection of surface cracks View project 
3 Ist Digital Avionics Systems Conference October 2012 - Williamsburg,VA.

\section{Experimental Approach to an Optical Wireless Interface for an Avionics Data Bus}

Authors:

Javier Perez-Mato (IDeTIC - ULPGC) [jperez@idetic.eu] Rafael Perez-Jimenez (IDeTIC - ULPGC) [rperez@idetic.eu] Joshua Tristancho (EETAC - UPC) [joshua.tristancho@upc.edu] Curd S.Zechmeister (IEEE Member) [curdzechmeister@gmail.com] 


\section{CONVENTIONAL AVIONICS}

- Connectivity between different control surfaces is usually implemented by the use of mechanical connectors and cables.

- Pulleys and wires

- Fly-By-Wire (FBW)

- Fly-By-Light (FBL)
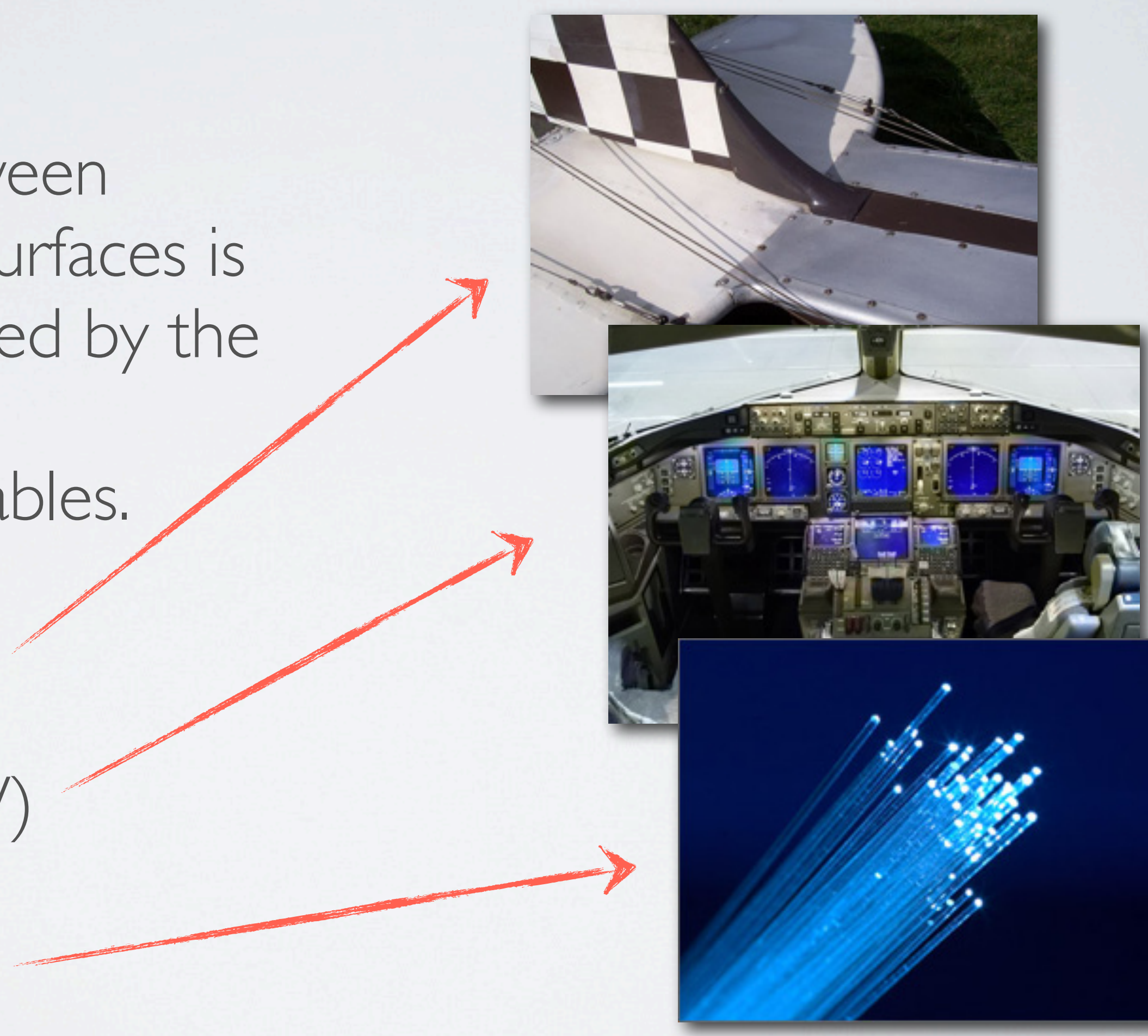


\section{WIRELESS AVIONICS}

- Avionic systems can be improved by using a topology and interconnectivity scheme like the one tipically used in Wireless Sensor Networks (WSN).

- The main advantages of this technology could be:

- Harness and weight reduction achieved by removing physical cables and connectors.

- Increased freedom when placing sensors or actuators across the aircraft's body.

- Greater reliability due to optical link redundancy. 


\section{THE EMI PROBLEM}

- Instruments within an aircraft are highly sensitive to electromagnetic interference (EMI).

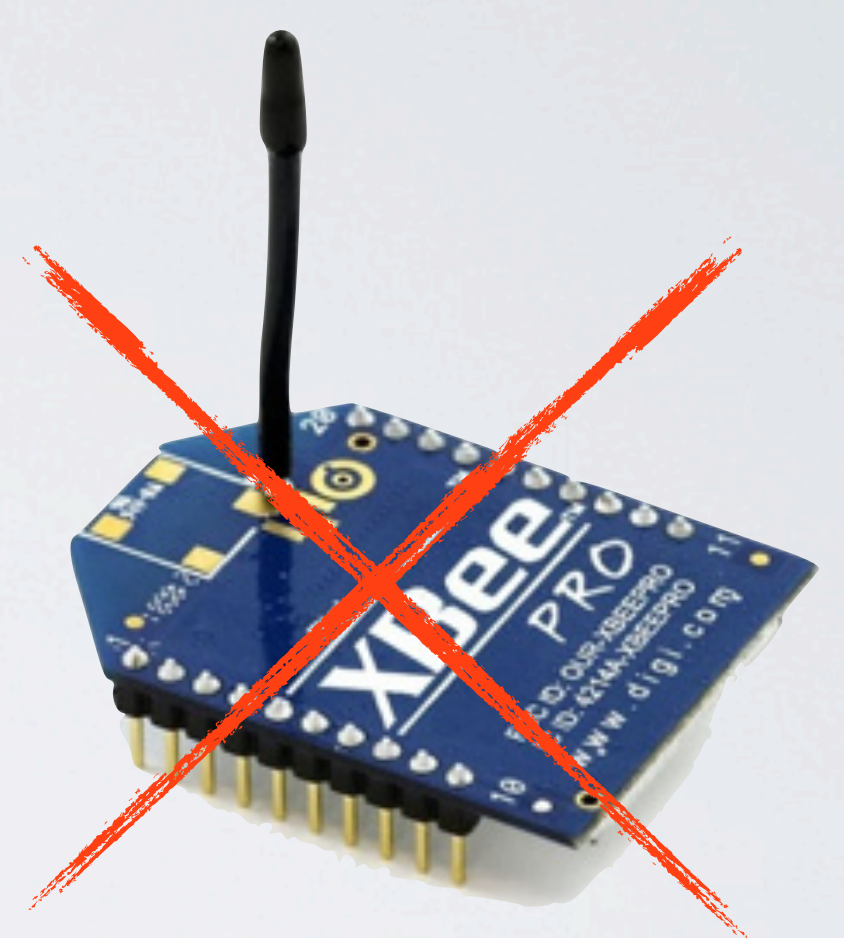

- This fact prevents classical RF wireless networks to be implemented.

- Solution: Use.... LIGHT!!

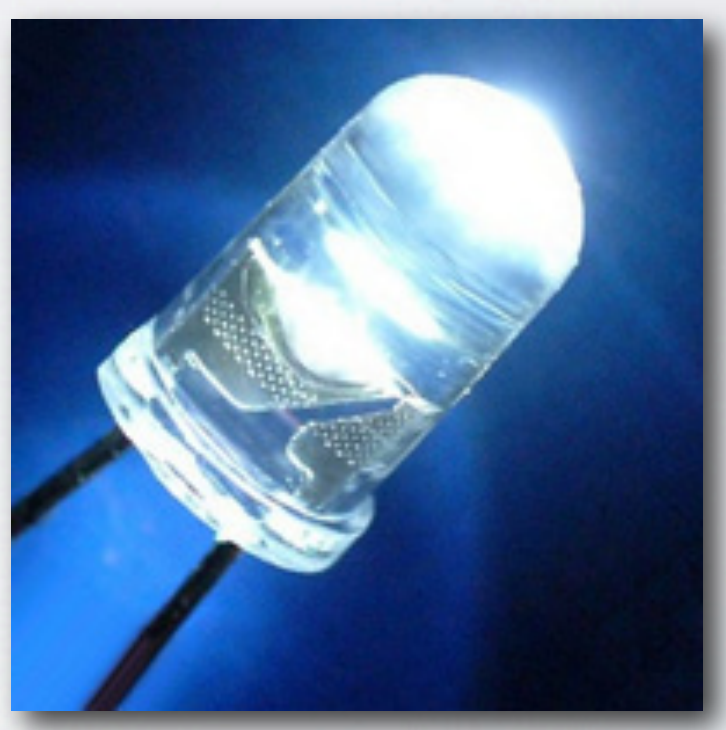




\section{WIRELESS OPTICAL LINKS}

- Light sources provide no EMI capable of interfering with other electronic equipments.

- LEDs can be pulse-modulated in order to transmit information ranging from a few bps up to several Mbps.

- Lasers can be used to achieve larger distances and higher data-rates.

- Optical wireless links have been widely used in many critical operations throughout the history of communications (Eg. ESA - OWLS Project). 


\section{ARINC 429 AVIONICS DATA BUS}

- Defines the electrical, word structure and protocol characteristics for the implementation of a secure and reliable avionics data bus.
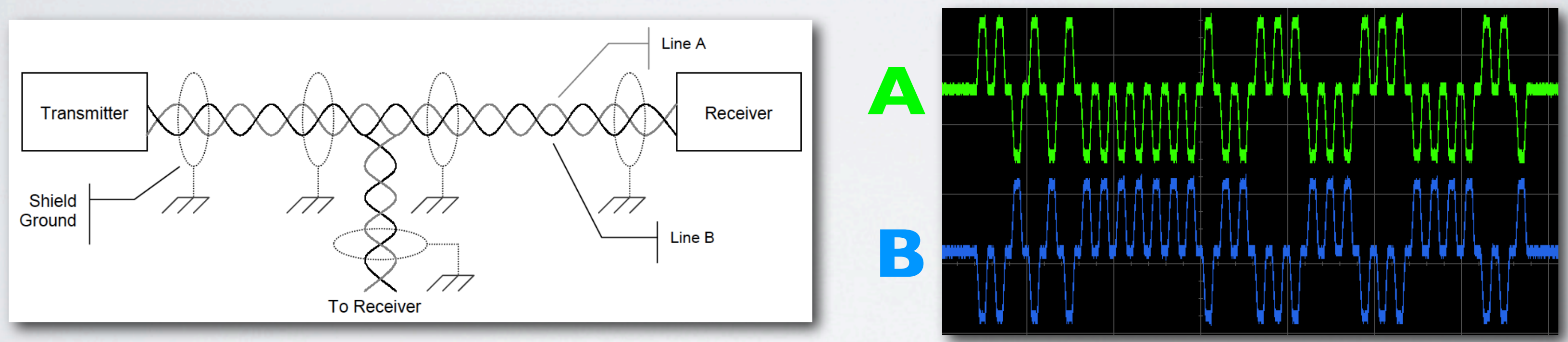

- Data is transmitted in 32-bit data words by means of a shielded twisted-pair cable ( $A$ and $B$ signals), using a complementary, tri-state, bi-polar, RZ line coding scheme. 


\section{OPTICAL WIRELESS INTERFACE}
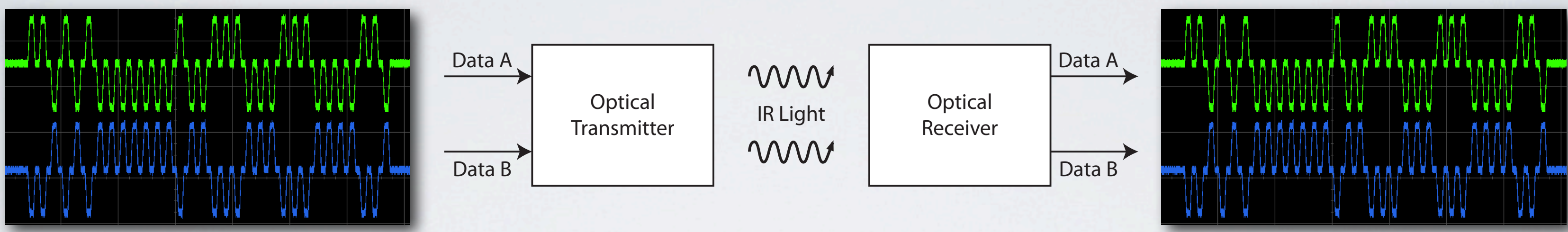

- A completely transparent optical wireless interface will be provided. Any avionics equipment at either end of the interface should remain unaware of its presence in the bus.

- To ensure compatibility with existent avionics hardware, the optical wireless interface will be tested with a real Attitude Director Indicator (ADI). 


\section{HARDWARE-IN-THE-LOOP (HIL) SIMULATOR \\ Block Diagram}

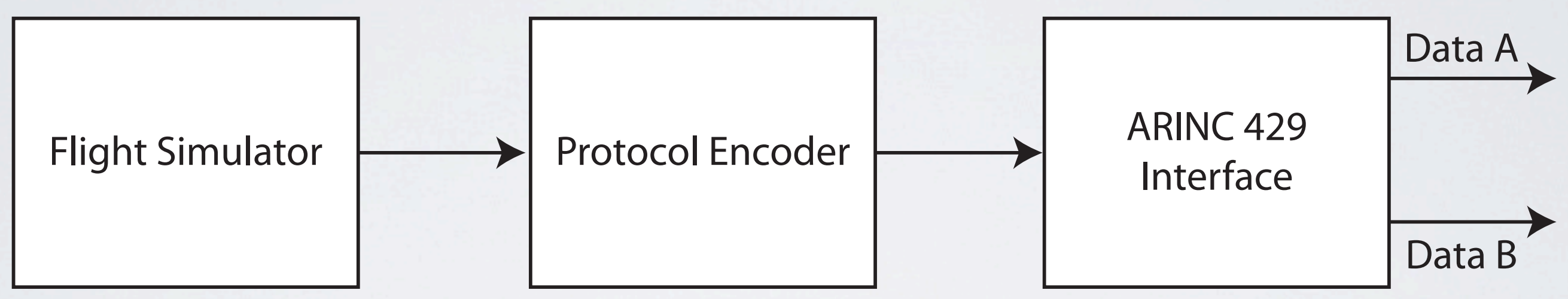

- This device serves as an interface between a flight simulator software and the ARINC 429 avionics bus.

- To correctly interface with the ADI the HIL simulator extracts pitch and roll values from the flight simulator and codes them into valid ARINC 429 data words. 


\section{HARDWARE-IN-THE-LOOP (HIL) SIMULATOR}

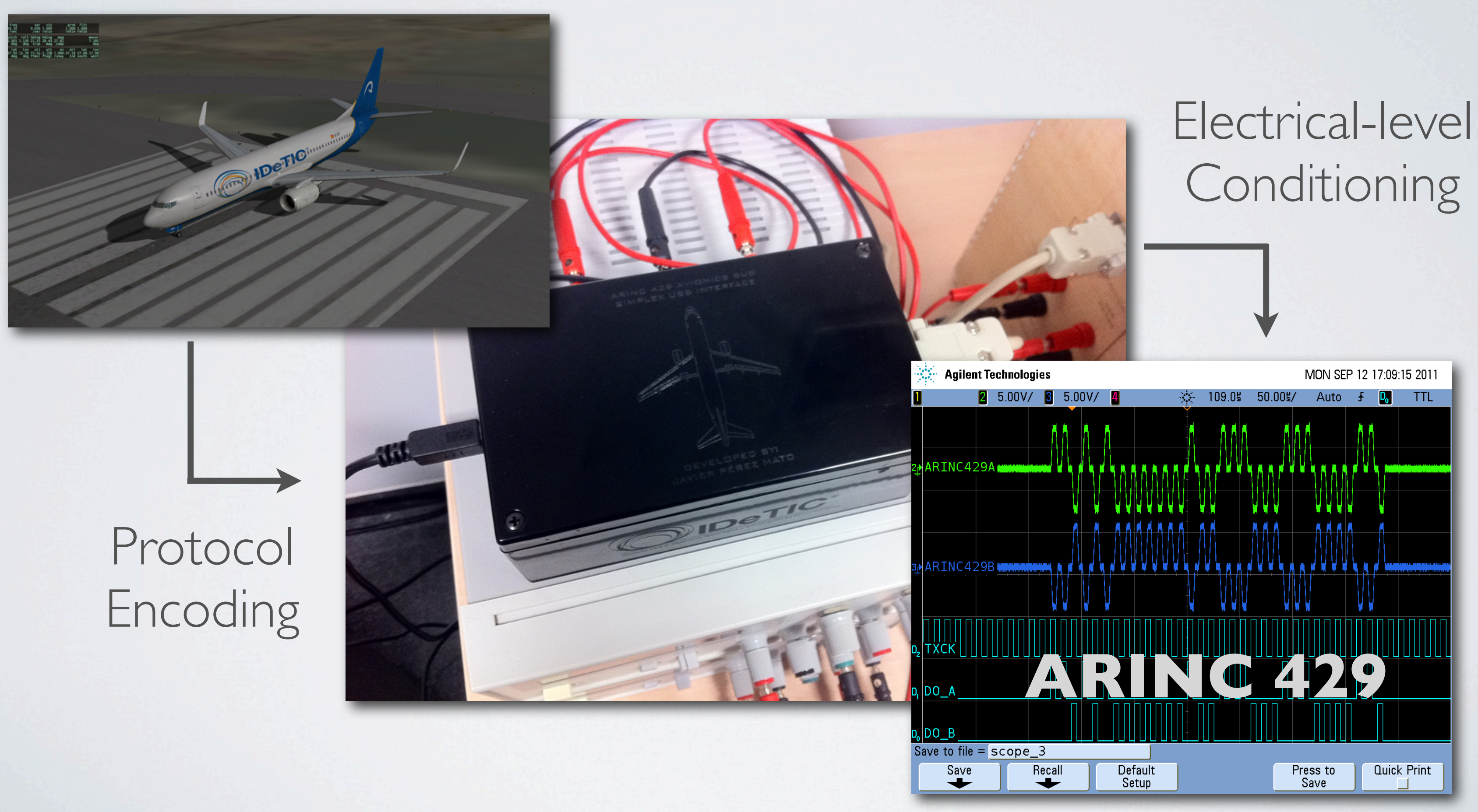




\section{OPTICALTRANSMITTER}

\section{Block Diagram}

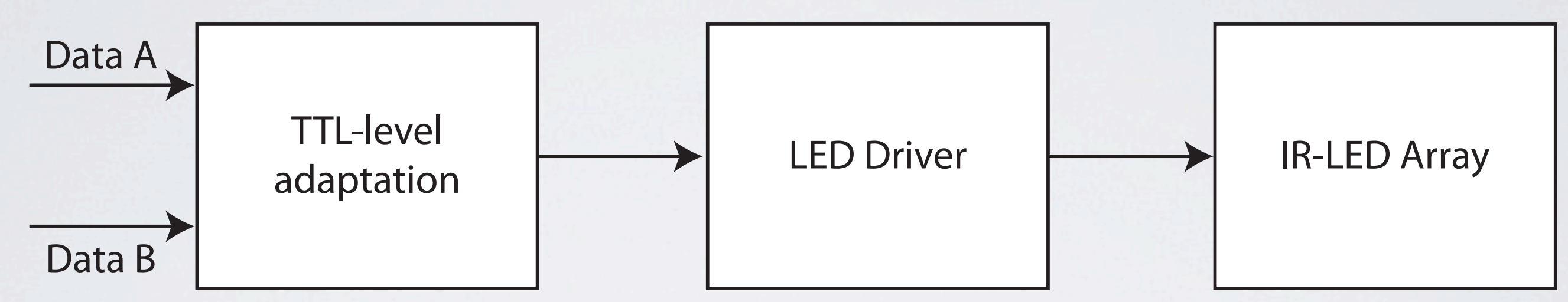

- Serves as an interface between the physical layer of the ARINC 429 avionics bus and the proposed optical wireless link.

- Accepts ARINC 429 A and B signals and transforms them into light pulses ready to be transmitted by an array of IRLEDs. 


\section{OPTICALTRANSMITTER}

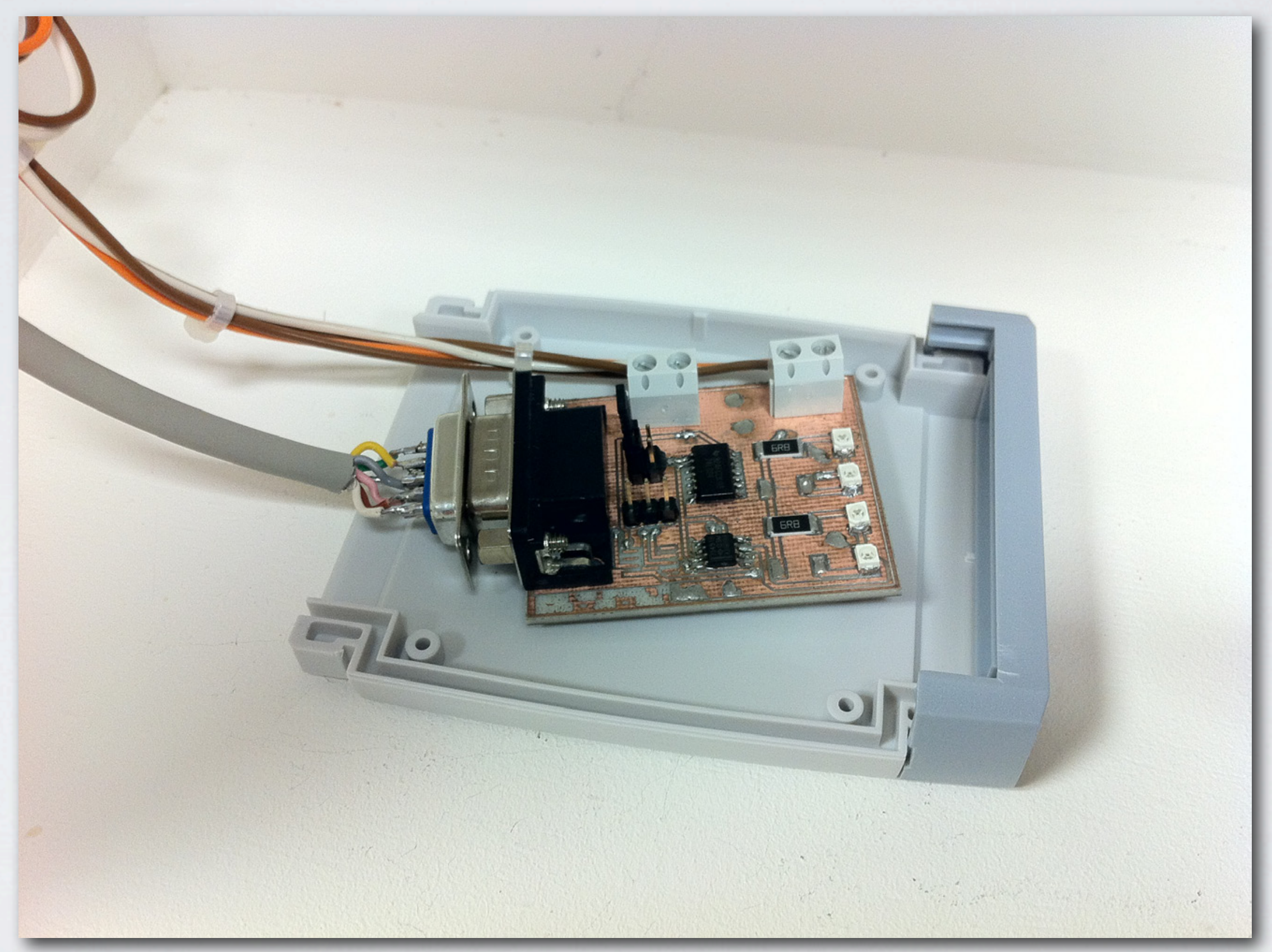




\section{OPTICAL RECEIVER}

\section{Block Diagram}

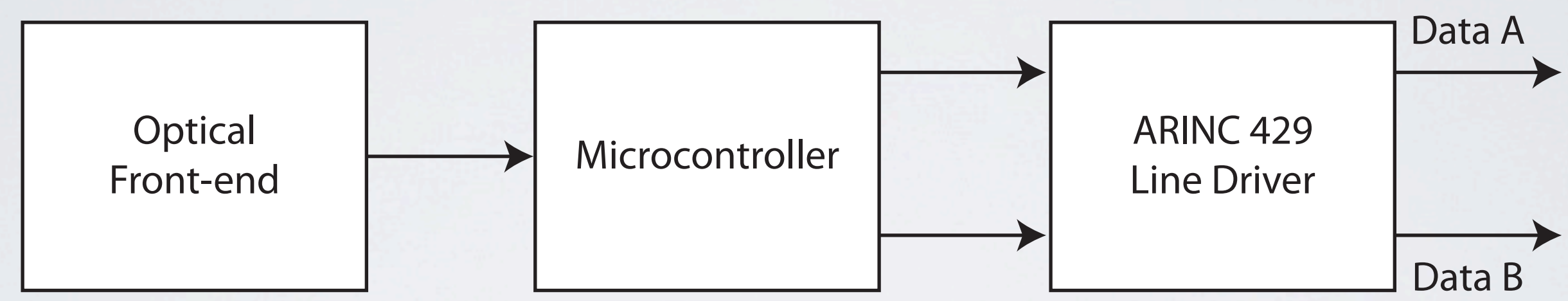

- Detects light pulses generated by the IR-LEDs in the optical transmitter and transforms them into a digital TTL signal.

- From this TTL signal both ARINC 429 A and B signals are fully recovered, ready to be sent over another wired segment of the ARINC 429 avionics bus. 


\section{OPTICAL RECEIVER}

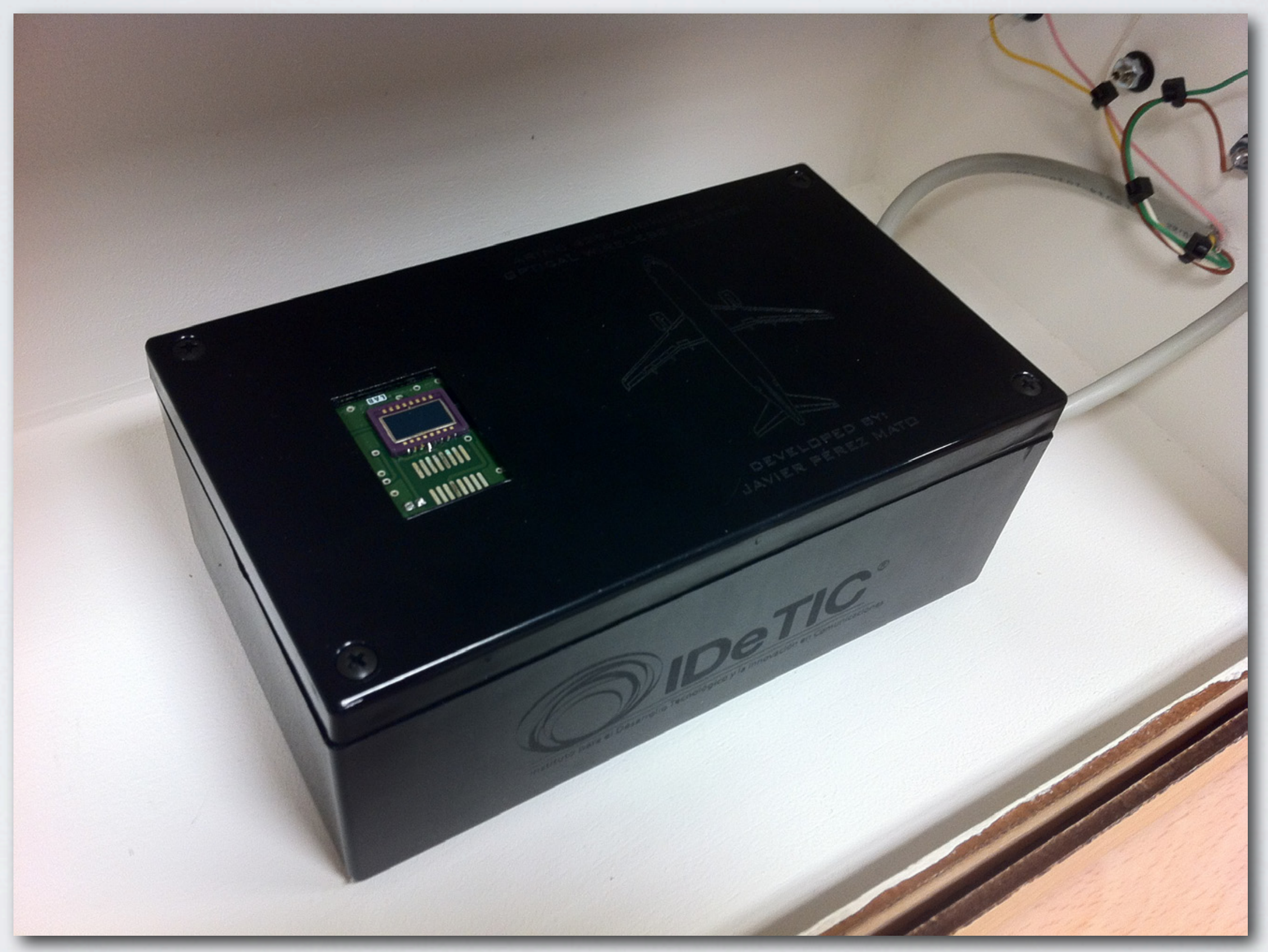




\section{EXPERIMENTAL SETUP}
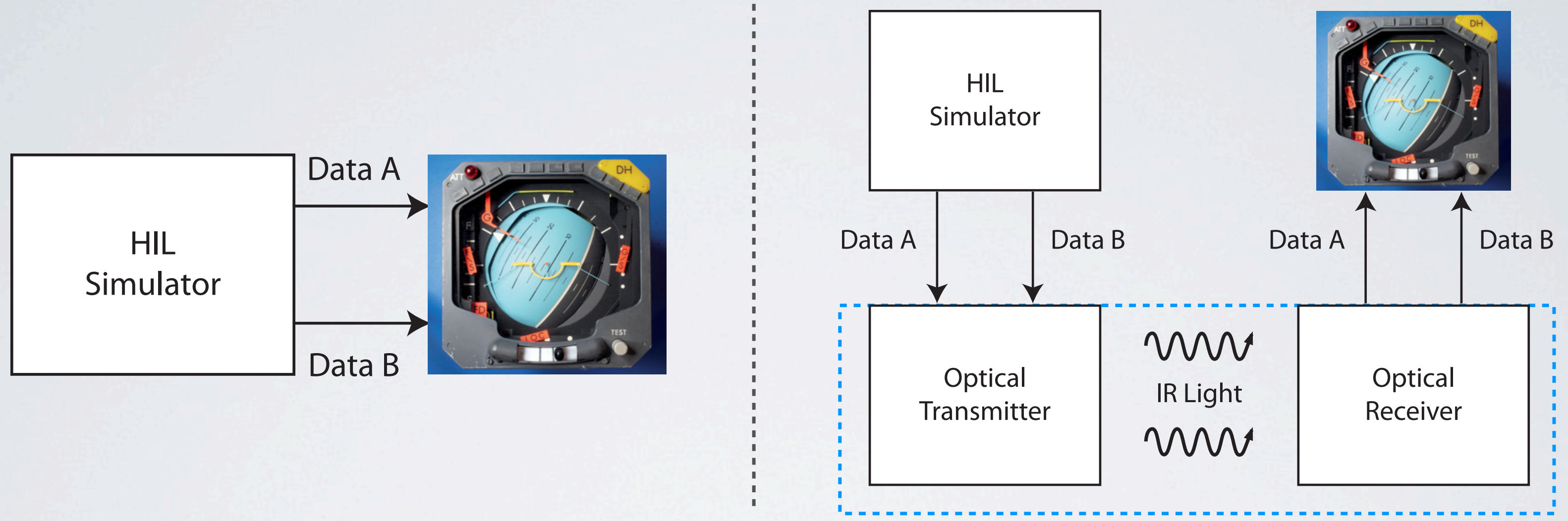

- Real avionics hardware was used to validate both the HIL simulator and the optical wireless interface.

- Both behavioural and electrical-level tests were performed in order to ensure compatibility with the ARINC 429 standard definition. 


\section{EXPERIMENTAL SETUP}
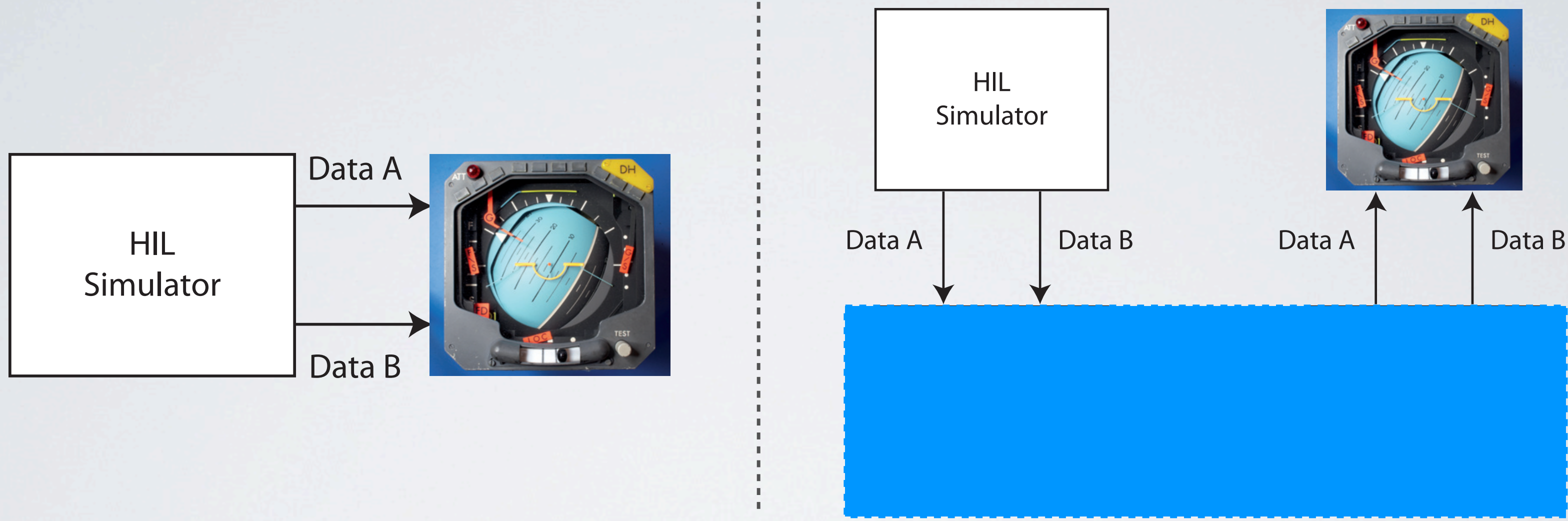

- Real avionics hardware was used to validate both the HIL simulator and the optical wireless interface.

- Both behavioural and electrical-level tests were performed in order to ensure compatibility with the ARINC 429 standard definition. 


\section{DEMO VIDEO}

This video shows the optical wireless interface driving a real ADI by transmitting valid ARINC 429 pitch and roll data words generated by a flight simulator connected to the HIL simulator.

http://www.youtube.com/watch?v=pWYorlfUM5I 


\section{RESULTS}

Rise and Fall Times (A and B Signals)

ARINC 429 Specification: $1.5 \mu \mathrm{s} \pm 0.5 \%$
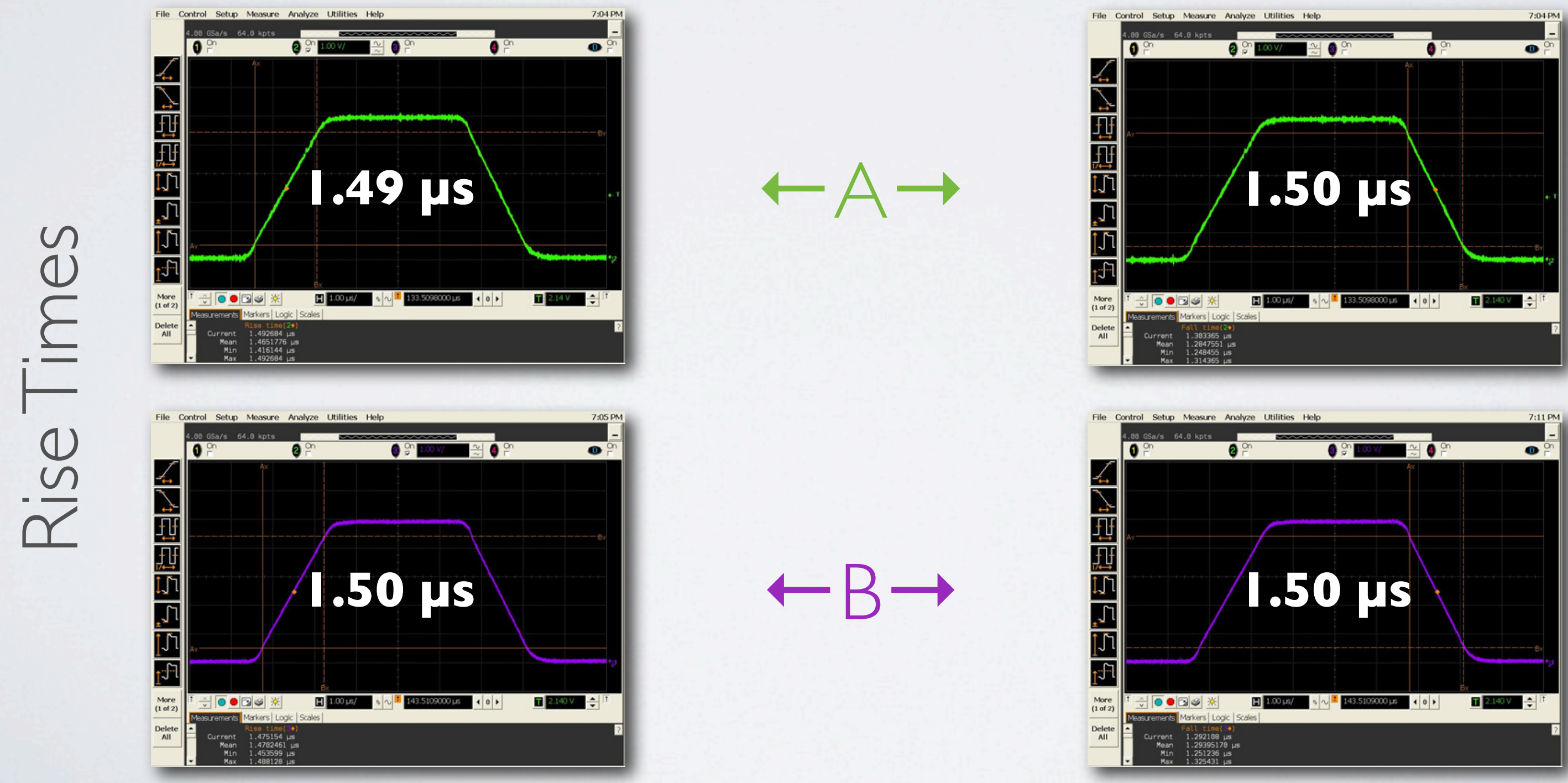


\section{RESULTS}

Bit and Half-Bit Duration (A and B Signals)

ARINC 429 Specification: $10 \mu s \pm 2.5 \% / 5 \mu s \pm 5 \%$

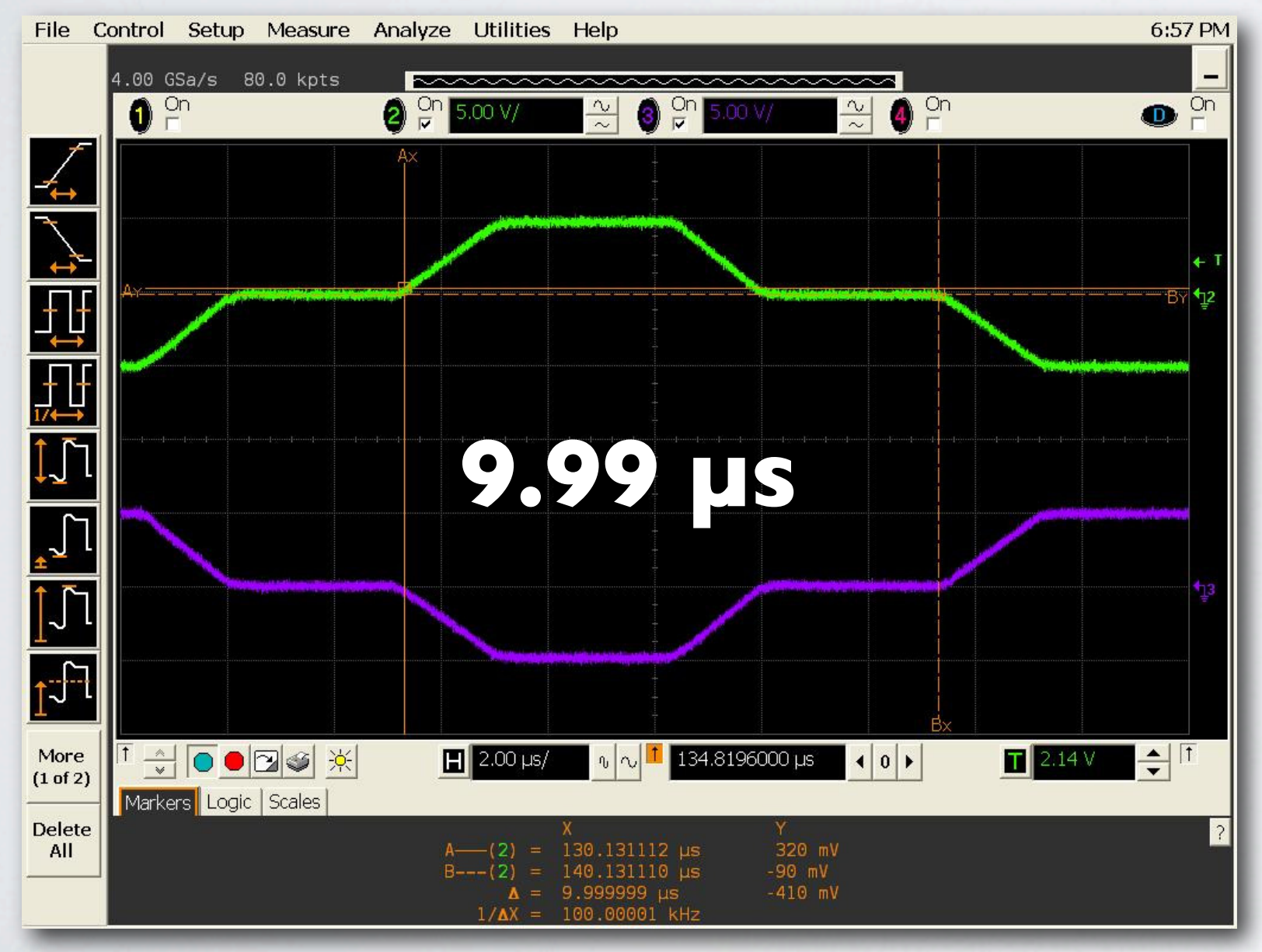

Bit Duration

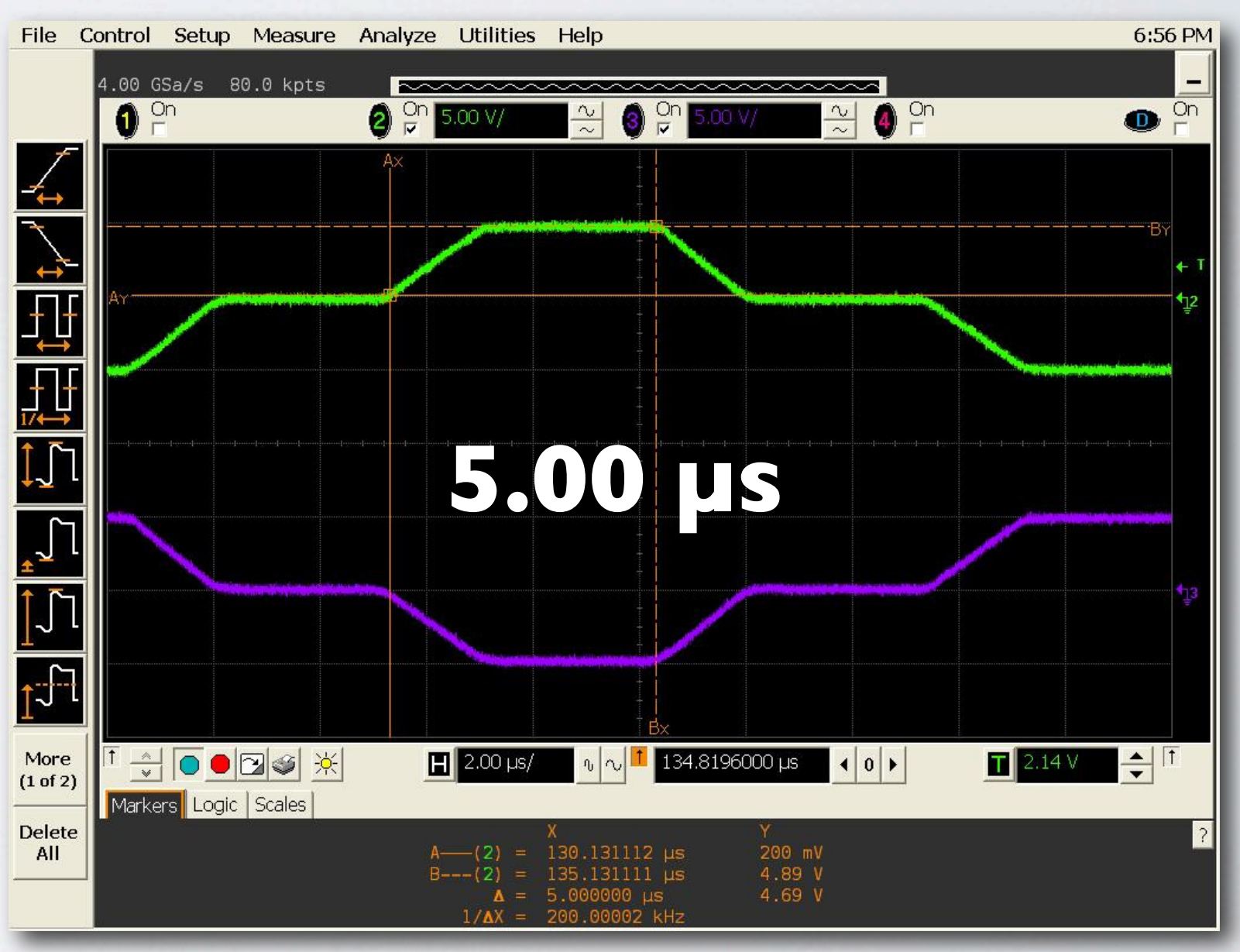

Half-Bit Duration 


\section{RESULTS}

Voltage Levels and Transmission Delay (A and B Signals) ARINC 429 Specification: $5 \mathrm{~V}, 0 \mathrm{~V},-5 \mathrm{~V} \pm 0.5 \mathrm{~V}$

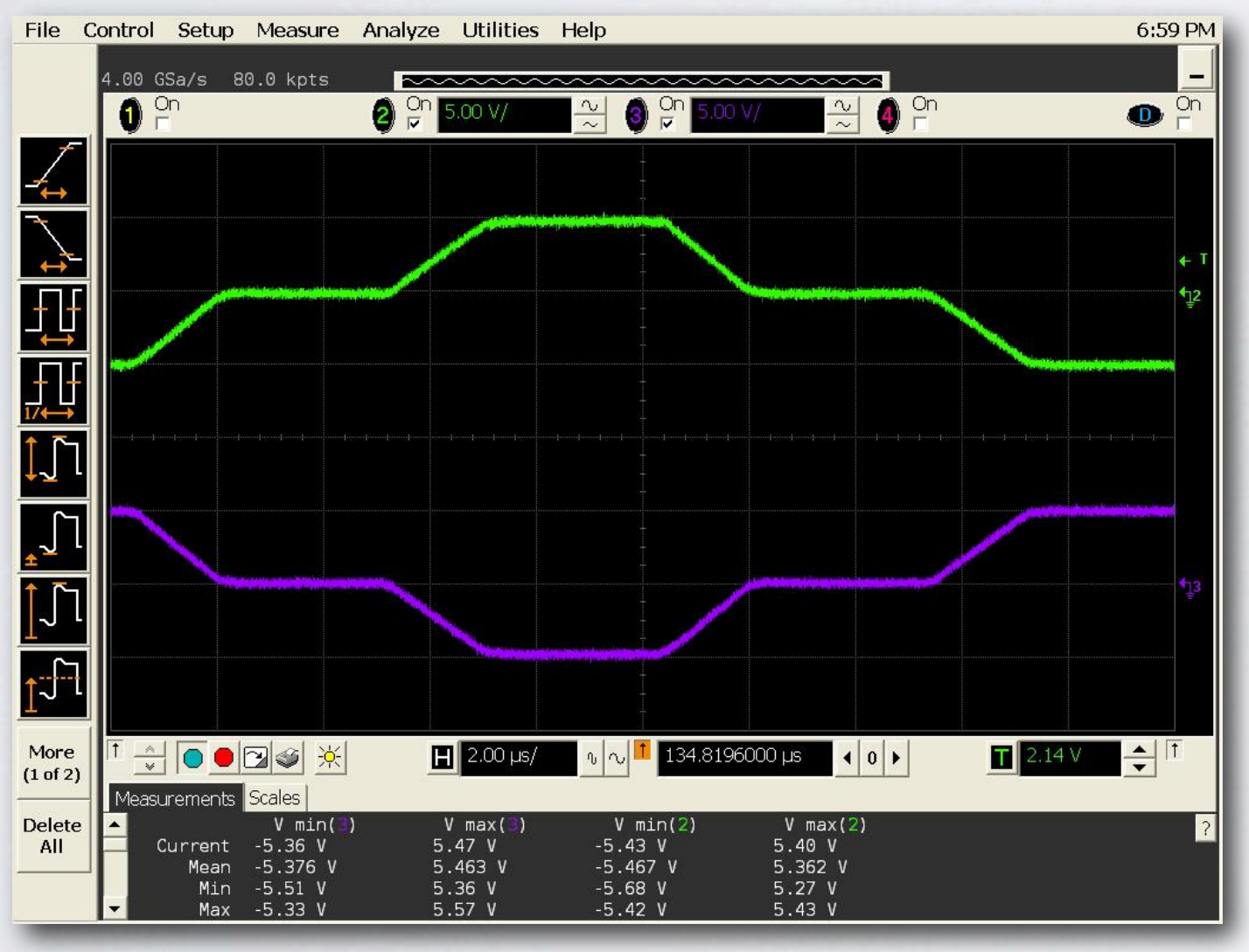

\begin{tabular}{|c|c|c|c|}
\hline & HIGH & NULL & LOW \\
\hline A & $5.36 \mathrm{~V}$ & $0.12 \mathrm{~V}$ & $-5.43 \mathrm{~V}$ \\
\hline B & $5.42 \mathrm{~V}$ & $0.11 \mathrm{~V}$ & $-5.38 \mathrm{~V}$ \\
\hline
\end{tabular}




\section{CONCLUSIONS}

- The implementation and feasiblity of an optical wireless interface for the ARINC 429 has been demonstrated.

- A low-cost HIL simulator for the ARINC 429 has also been developed, which is able to replicate real flight data within a laboratory environment.

- The developed interface complies with all electrical and timing restrictions described in the ARINC 429 definition. 


\section{CONCLUSIONS}

- Avionics network topologies can benefit from the advantages of wireless communications without introducing any hazardous sources of EMI.

- The proposed solution can be easily ported to other avionics data buses.

- A dramatic reduction in weight can be achieved due to the removal of electrical wires, helping to reduce fuel consumption and achieve a greater efficiency. 


\section{Ist Digital Avionics Systems Conference October 2012 - Williamsburg,VA.}

"Experimental Approach to an Optical Wireless Interface for an Avionics Data Bus"

\section{Questions?}

For further information, please contact: Javier Perez-Mato (IDeTIC - ULPGC) [jperez@idetic.eu] 